\title{
AGE-RELATED CHANGES OF THE HUMAN CILIARY MUSCLE. A QUANTITATIVE MORPHOMETRIC STUDY
}

\author{
SVENJA TAMM ${ }^{a}$, ERNST TAMM ${ }^{b}$ and JOHANNES W. ROHEN ${ }^{b}$ \\ "Department of Ophthalmology, Schwabachanlage 6 and 'Department of Anatomy. Krankenhausstr. 9. \\ University of Erlangen-Nürnberg, D-8520 Erlangen (F.R.G.)
}

(Received August 19th, 1991)

\section{SUMMARY}

The age-related changes of the ciliary muscle of human eyes (33-87 years) were studied on histological meridional sections. Eighty-five melanoma eyes and 10 eyes of normal donors were investigated. The total area and the length of the muscle, the area of the three main portions and the distance of the inner apex of the muscle to the scleral spur were determined and correlated with age. Total area and length of the muscle show a continuous and significant decrease with age. The area of the longitudinal and reticular portion continuously decreases, whereas the area of the circular portion significantly increases with age. The decrease in area is more pronounced in the longitudinal portion than in the reticular portion of the muscle, which shows an age-related increase in connective tissue. In addition, the distance of the inner apex of the muscle to the scleral spur shortens continuously. Thus, with increasing age the ciliary muscle adopts an anterior-inward position. A similar form is seen in young eyes after ciliary muscle contraction only. There might be a functional relationship between the observed age-changes in the ciliary muscle system and the phenomenon of the so-called 'lens paradox' (steepening of the anterior and posterior curvatures of the disaccommodated lens with age).

Key words: Ageing; Presbyopia; Ciliary muscle; Human eye; Morphometry; Histology

\section{INTRODUCTION}

Presbyopia, the age-related loss of accommodative amplitude, is a universal, consistent and predictable consequence of human ageing. It has been suggested that lenCorrespondence to: Ernst Tamm, Anatomisches Institut, Universität Erlangen-Nürnberg, D-8520 Erlangen, Germany. 
ticular factors, like a decreased elasticity of the lens capsule [1]. at decrease in the refractive index of the lens [2], or changes in architecture of ciliary holy and conula [3] contribute to presbyopia.

Cynomolgus monkeys (Macaca fascicularis), or rhesus monkeys ( Macaca mulatua) show an age-related decline in accommodative amplitude, which parallels the lows of voluntary accommodation in humans [4.5]. In presbyopic rhesus monkeys, the ciliary muscle loses its configurational response to topically administered pilocarpine [6]. Also video-recording of ciliary body coronal width, after central electrical stimulation of young and old monkeys, shows loss of measurable ciliary body movement with age. indicating loss of effective ciliary muscle contraction [7]. Thus the ciliary muscle of old monkeys is not able to move anterior-inwardly during stimulation, but is restrained to a posterior position which is typical for the relaxed muscle of young animals. These findings suggest that age changes in the ciliary muscle and its posterior attachment contribute to presbyopia in monkey eyes

It is not known whether similar processes are also involved in human presbyopia. In contrast to the findings in monkeys. it has been reported that the ageing human ciliary muscle acquires a position far anterior-inwardly. similar to that of at contracted muscle [8.9]. To obtain comparable data with those on monkey eyes [6] we investigated the age-related changes in ciliary muscle structure and position in human eyes using morphometrical methods.

\section{MATERIALS AND METHODS}

Ninety-five eyes from 53 female and 42 male human donors (age $33-87$ years. mean 63.2. median 65.17) were investigated. Eighty-five eyes (46 female, 39 male) were from the files of the Ophthalmic Pathological Laboratory of the Department of Ophthalmology, University of Erlangen-Nürnberg (Head: Prof. Dr. G.O.H. Naumann) and had been enucleated because of malignant posterior choroidal melanoma. The age of the tumor eyes ranged from 33-87 years. In addition 10 human autopsy eyes ( 6 female, 4 male, age $41-84$ ) were studied. The autopsy eyes had been enucleated 2-22 h after death. None of the donors had a history of abnormalities in the anterior segment of the eye. In none of the tumor eyes was the anterior half of the eye infiltrated by the tumor. No donor had undergone intracular surgery before or showed signs of secondary glaucoma. The mean length of the bulb after fixation was $23.6 \pm 1.1 \mathrm{~mm}$ (mean \pm S.D.). in none of the eyes was the bulb smaller than $22 \mathrm{~mm}$ or larger than $26 \mathrm{~mm}$. Before enucleation, the lumor eyes had been treated with tropicamide (Mydriaticum Roche ${ }^{(i)}$ ). The autopsy eves were incubated

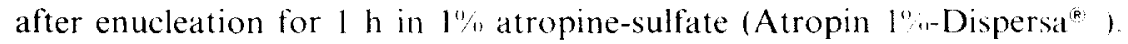

Immediately after enucleation (tumor eyes) or after incubation in atropine (autopsy eyes), the eyes were fixed as a whole in a solution of $4 \%$ paraformaldehyde and $1 \%$ glutaraldehyde for 4-5 days. After fixation. the eyes were dissected with a razor blade by two parallel meridional cuts, one on each side of the optic nerve entrance. at a distance of $2-4 \mathrm{~mm}$ from the nerve head. The cuts extended all through the eye 
to the cornea. The orientation of the cut was horizontally in the autopsy eyes. In the tumor eyes, the orientation was chosen so as to avoid cutting the tumor (for details, see Naumann [10]). The middle part of the bulb (containing the tumor) was embedded in paraffin in the usual way [11]. Paraffin sections were made at a thickness of $5 \mu \mathrm{m}$. The sections were stained with Masson's trichrome stain. Care was taken that the orientation of the paraffin block was such that the central region of the pupil and of the optic nerve head were both present in one section.

From all sections, drawings outlining the perimeter of the ciliary muscle, the chamber angle and the adjacent sclera were made using a drawing microscope (Zeiss Winkel 127012) at a magnification of $\times 91$. In addition, a line was drawn between the meridional and the reticular portion of the muscle. The drawing was checked at higher magnifications. Furthermore, the outlines of all muscle bundles in the region of the inner apex of the muscle, which contained only circular muscle cells, were drawn and their areas added as a measure of the circular portion of the muscle. Muscle bundles containing both transversely and obliquely cut muscle bundles were regarded as parts of the reticular portion. Thus the drawings of the circular portion outlined muscle cell area only, while the outlines of both reticular and longitudinal portion included both area of muscle cells and area of intramuscular connective tissue.

With a morphometric device (Morphomat 30, Fa. Zeiss) the total area of the ciliary muscle, the areas of its different portions, and its length and width were evaluated. In addition, the inner apical position of the muscle was measured. A perpendicular was dropped from the widest part of the area containing the muscle bundles of the circular portion to the outer outline of the longitudinal portion of the ciliary muscle. The distance between the point where the two lines met and the anterior tip of the longitudinal portion of the ciliary muscle at its insertion to the scleral spur was evaluated as a measure of the 'inner apical position' of the ciliary muscle (Fig. 1).

To check for regional differences, measurements from different quadrants of the eyes were grouped separately. Due to the different positions of the tumor, the plane of the sectioning was different in the individual tumor eyes. Therefore, the tumor eyes were subdivided in two groups: (a) eyes cut horizontally (position of the ciliary muscle between 2 and 4 o'clock or 8 and 10 o'clock, e.g. nasal and temporal quadrant); (b) eyes cut vertically (position of the ciliary muscle between 11 and 1 o'clock and 5 and 7 o'clock, e.g. upper and lower quadrant). The measurements from each different quadrant were then evaluated separately.

For each parameter, the mean of three measurements, which were done on different days, was taken and plotted as a function of age. Correlations were defined as significant if $P \leq 0.01$ according to the Geigy Scientific Tables [12]. For testing the difference between the correlations of the different quadrants, a two-tailed Student's $t$-test was used $(P \leq 0.05)$. Additionally, the ratio between area of muscle cells and intramuscular connective tissue was estimated semiquantitatively.

The three different portions of the muscle (longitudinal, reticular and circular) 


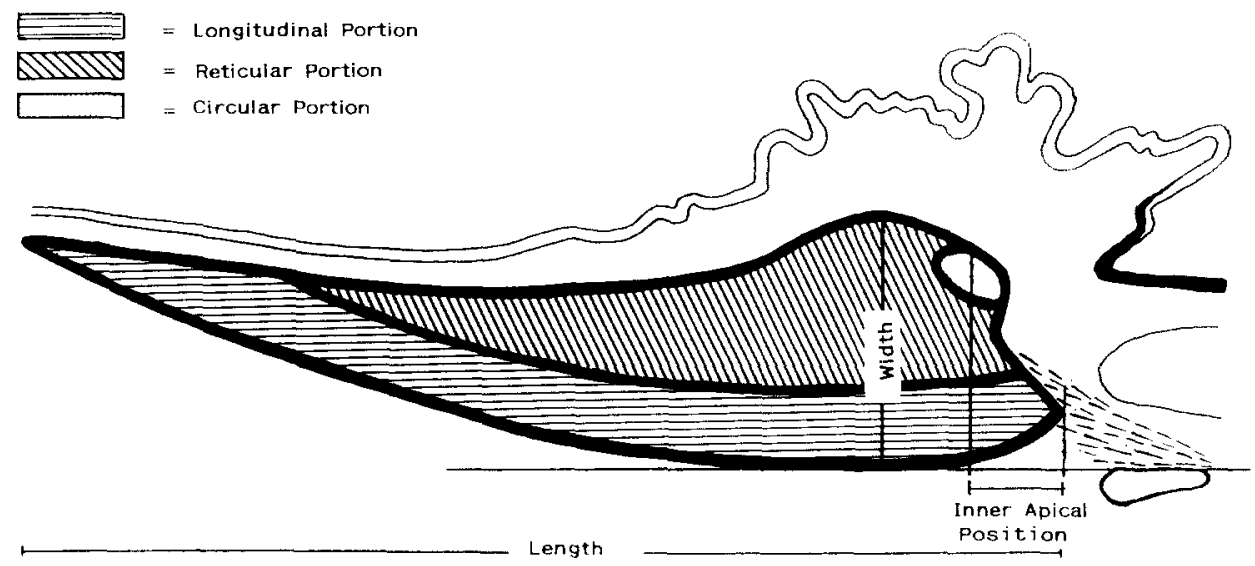

Fig. 1. Schema for topographic analysis of ciliary muscle. By digitization of cilitry muscie drawings. measurements were made of ciliary muscte length (anterior-posterior distance along outer longitudinal edge from posterior tip to anterior insertion at scleral spur), width, position (anterior-posterior distance from inner apex to scleral spur, perpendicular to width of inner apex), and area of entire muscle and longitudinal. reticular and circular components.

were evaluated separately. The grading was 0 , if no connective tissue was present between the muscle bundles. + , if the connective tissue comprised $\leq 20 \%$ of the area of the muscle portion, ++ for $<50 \%$ and +++ for $\geq 50 \%$.

\section{RESULTS}

\section{Differences in the circumference}

Comparison of the measurements of the temporal quadrant and the nasal quadrant of the horizontally sectioned eyes showed that the differences between the two were not significant (for each parameter $t$-test: $P>0.05$ ). The same was the case for the measurements of the upper and lower quadrant of the vertically sectioned eyes $(P>0.05)$. The data from both sides of each individual eye were therefore treated together and the mean values were calculated.

When the mean values of both horizontally and vertically sectioned eyes were similarly compared, the differences between both groups of eyes was again not significant (for each parameter, $P>0.05$ ). Therefore, for the final evaluation of each parameter, the mean values of all individual eyes were treated together.

The total area of the ciliary muscle measured on histological meridional sections shows a continuous and highly significant decrease with increasing age (correlation coefficient $(r)=-0.74, P>0.001$. Fig. 2). This is concomitant with a marked decrease in the length of the muscle $(r=-0.90, P \leq 0.001$, Fig. 3). Thus the mean length of the ciliary muscle, which measures approx. $4 \mathrm{~mm}$ in the 4 th decade of life. 


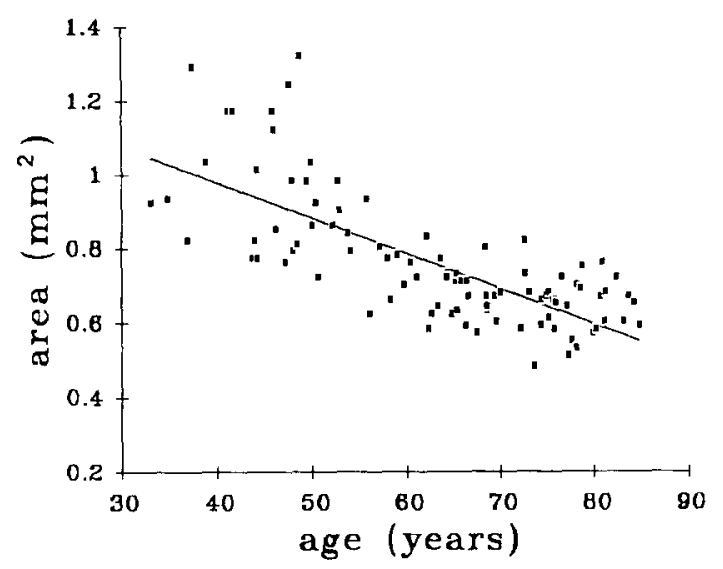

Fig. 2. Total meridional sectional area of the human ciliary muscle as a function of age. The total area shows a significant decrease with increasing age $(y=1.36-0.0095 x, r=-0.74, P \leq 0.001)$.

shortens through age 70-80 years by approx. one half. In contrast, the width of the muscle does not show a significant correlation with age $(r=-0.27, P \leq 0.05$, Fig. 4). Regarding the decrease in muscle area, differences between the different portions of the muscle were found. While the reduction in area of the longitudinal portion was highly correlated with age $(r=-0.83, P \leq 0.001$. Fig. 5), this was not the case for the reduction in area of the reticular portion $(r=-0.53, P \leq 0.001$, Fig. 6). In marked contrast to the rest of the muscle, the area of the circular portion showed a significant increase with age $(r=0.77, P \leq 0.001$, Fig. 7). This circular portion forms the inner apex of the muscle. In the younger eyes, the inner apex was obtusely

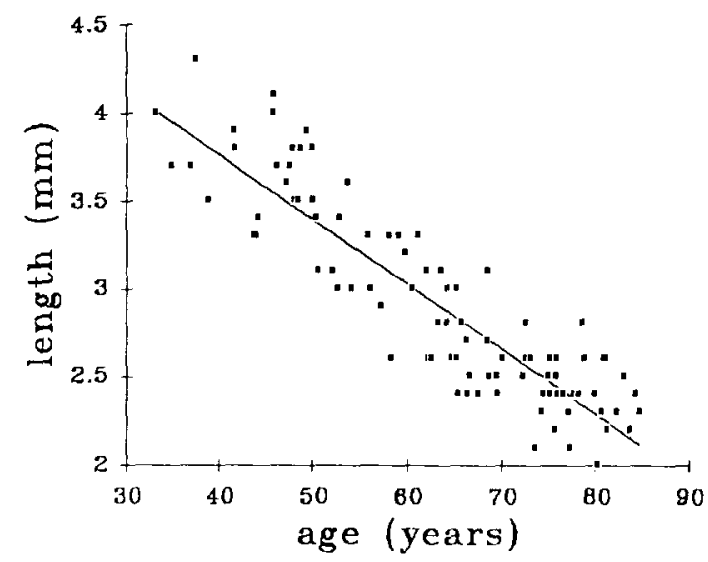

Fig. 3. Length of the ciliary muscle as a function of age. Ciliary muscle shortens significantly with age $(y=5.24-0.037 x, r=-0.90, P \leq 0.001)$. 


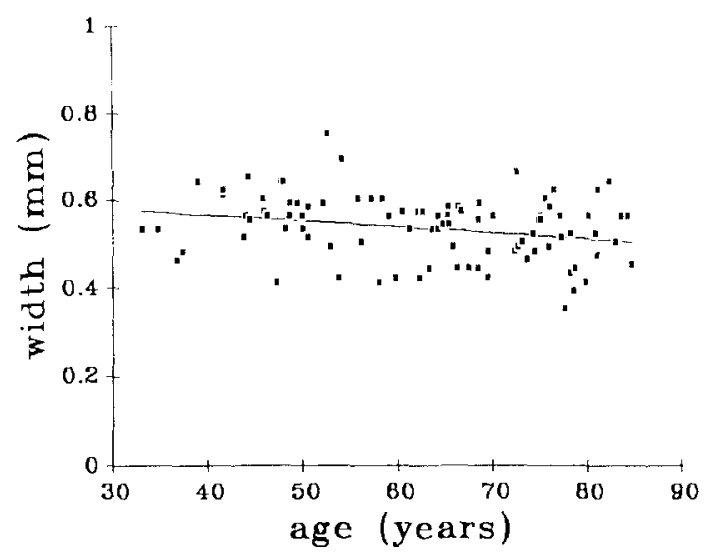

Fig. 4. Width of the ciliary muscle as a function of age. The width does not show a significant correlation with age $(y=0.62-0.0014 x, r=-0.27, P \leq 0.05)$.

angled and showed only a small amount of circularly oriented muscle cells. In these eyes, the inner apex was located approx. $0.4 \mathrm{~mm}$ behind the scleral spur (Figs. 8. 9A). With increasing age, an acutely angled inner apex was formed, which in the oldest eyes was located nearly as forward as (and in some sections anterior to) the scleral spur (Figs. 8, 9B, 9C). Thus the distance between the inner apex of the muscle and its insertion to the scleral spur, ('inner apical position'), showed a significant inverse correlation with age $(r=-0.74, P \leq 0.001)$. In these old eyes, with an acutely angled inner apex and a short inner apical position, well developed circular muscle bundles were invariably seen (Fig. 9C).

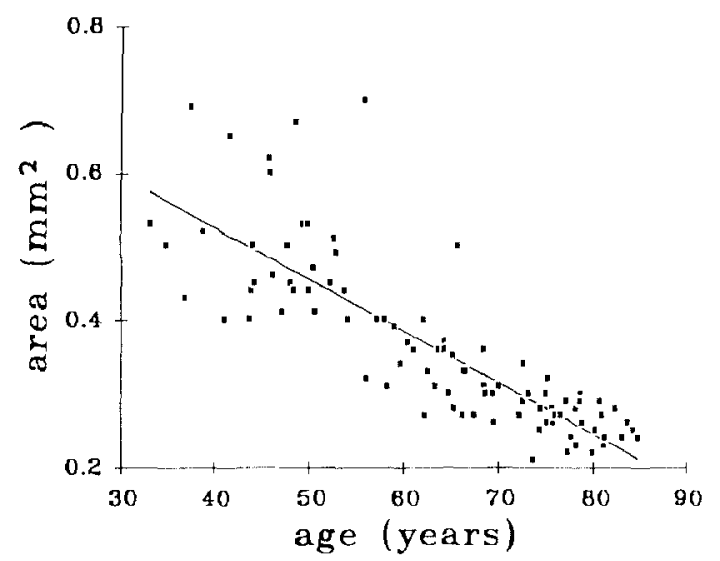

Fig. 5. Sectional area of the longitudinal portion of the ciliary muscle as a lunction of age. The longitudinal portion shows a reduction in area, which is highly correlated with age $(1=0.81-0.0070 x$. $r=-0.83 . P \leq 0.0011$. 


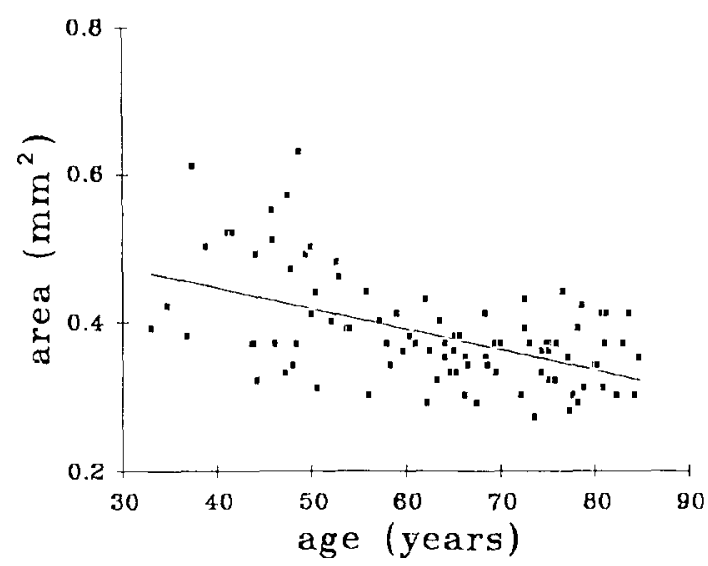

Fig. 6. Sectional area of the reticular portion of the ciliary muscle as a function of age. The age-related reduction in area of the reticular portion is significant $(y=0.56-0.0028 x, r=-0.53 . P \leq 0.001)$ but less pronounced than that of the longitudinal portion area.

With increasing age, ciliary muscle also showed a marked increase in intramuscular connective tissue (Table I). The increase in connective tissue was, however, not evenly distributed throughout the muscle, but showed differences between the different portions of the muscle. In eyes of humans younger than 50 years, there were only slight amounts of connective tissue fibers present between the muscle bundles of the longitudinal portion of the ciliary muscle. Even in the eyes of humans aged 50-85 years, the amount of connective tissue in the longitudinal portion never

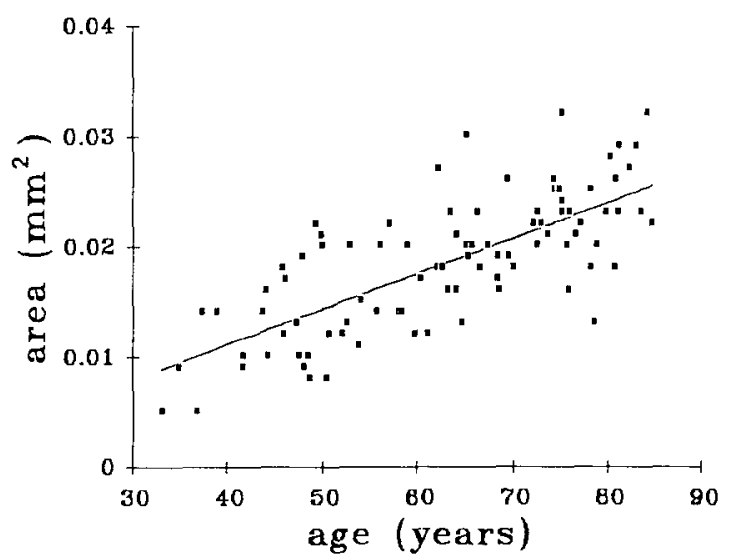

Fig. 7. Sectional area of the circular portion of the ciliary muscle as a function of age. In contrast to the other portions of the muscle, the area of the circular portion shows a significant increase with age $(y=$ $-0.0016+0.00032 x, r=0.77, P \leq 0.001$ ). 


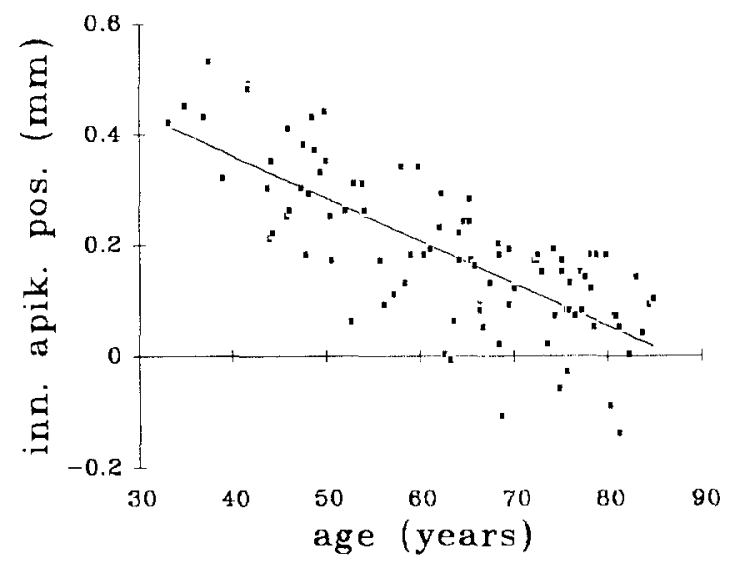

Fig. 8. Inner apical position of the ciliary muscle as a function of age. The distance between the inner apex of the muscle and its insertion to the scleral spur shows a significant inverse correlation with age $(y=0.67-0.0077 x, r=-0.74, P \leq 0.001)$.

constituted more than approx. $20 \%$ of the total area of the longitudinal portion. This was in contrast to the reticular portion of the muscle. In the eyes of humans between age 30 and 40 years, the connective tissue of the reticular portion constituted approx. $20 \%$ of the total area of the reticular portion. The ratio between the area of connective tissue and the area of reticular muscle bundles was approx. 1:1 in eyes of humans aged 50-60 years. In humans older than 60 years, the connective tissue of the reticular portion usually encompassed more than half of the total area of the reticular muscle portion. The large blood vessels and nerves were surrounded by a thick connective tissue sheath. Additionally, all muscle fiber bundles appeared thinned and were separated by dense connective tissue bands. From age 50 and older, the bundles of the circular portion were separated from the reticular portion by a large mass of connective tissue, which hyalinized with increasing age. The areas of hyalinization were continuous with the similarly hyalinized connective tissue of the stroma of the ciliary processes. In contrast, the stroma of the iris root, which is situated anterior-inwardly to the circular portion, was not hyalinized and showed no marked increase in connective tissue with age.

Fig. 9. Ciliary muscle of 34- (A). 59-(B) and 80-year-old (C) human donors. The inner apex of the muscle. which consists mainly of the muscle's circular portion, changes its position throughout lifetime. (A) In the ciliary muscle of the 34-year-old donor, the inner apex (arrow) is located well posterior to the scleral spur (arrowhead). (B) In the eye of the 59-year-old donor, the inner apex of the muscle is located nearly as forward as the scleral spur. (C) In the 80-year-old donor, the inner apex of the muscle is located anterior to the scleral spur (paraffin sections, Masson's stain, $\times 50$ ). 

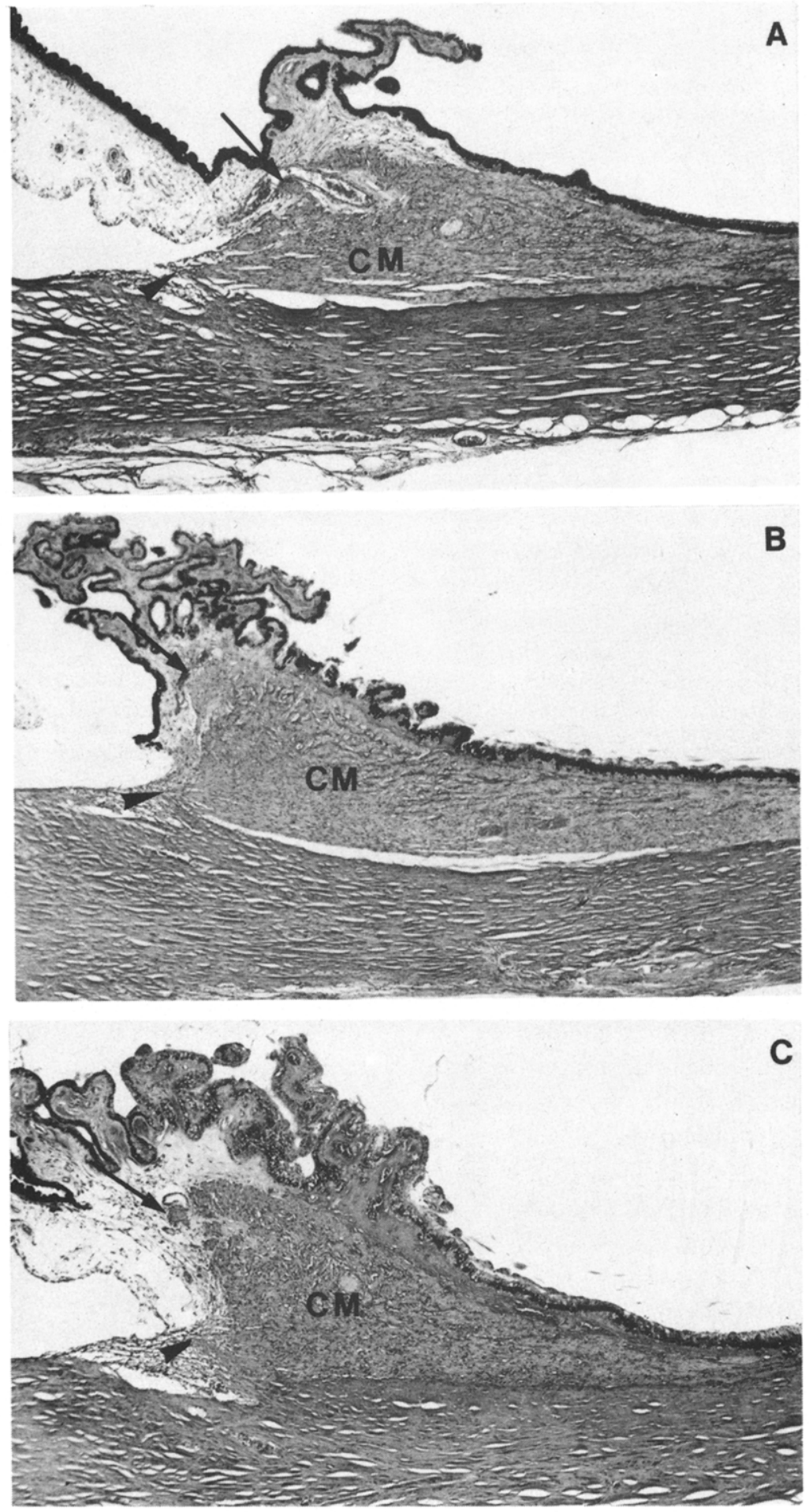
SEMIQUANTITATIVE EVALUATION OF THE PERCENTAGE OF INTRAMUSCLLAR CON. NECTIVE TISSUE AREA IN THE SECTIONAL. AREA OF LONGITUDINAL. AND RETICULAR MUSCLE PORTIONS

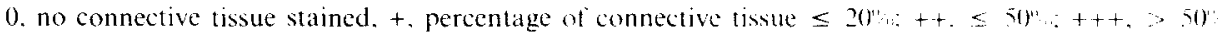

\begin{tabular}{lll}
\hline $\begin{array}{l}\text { Age } \\
\text { fears) }\end{array}$ & $\begin{array}{l}\text { Longitudinal } \\
\text { portion }\end{array}$ & $\begin{array}{l}\text { Reticular } \\
\text { portion }\end{array}$ \\
\hline $30-40$ & 0 & + \\
$40-50$ & 0 & ++ \\
$50-60$ & 0 & ++ \\
$60-70$ & $0-+$ & +++ \\
$70-80$ & + & +++ \\
$\geq 80$ & + & +++ \\
\hline
\end{tabular}

\section{DISCUSSION}

Our morphometric study shows that ciliary muscle continuously atrophies from age 30-80. Age-related atrophy of the ciliary muscle was also investigated by Stieve [9] who, however, described that this process starts later in life, beginning with age 55-60 years. The atrophy of the muscular elements is even more pronounced as at large concomitant increase in intramuscular connective tissue takes place with age. which has also been reported by other authors [8,9,13-15]. Findings of Stieve [9] and Rother et al. [16], that the ciliary muscle of women is more prone to atrophy cannot be confirmed.

The loss of contractile elements might cause a weakening of the ciliary muscle with increasing age. As the time course of these muscular changes is in marked correlation with the age-related loss of accommodative amplitude [17-19]. weakening of the ciliary muscle might contribute to presbyopia. Swegmark [20] and Fisher [21] stated that ciliary muscle power does not decline with age. However. these studies utilized very indirect methods such as impedance cyclography or in vitro passive stretch and lens deformation, to obtain information about ciliary muscle function. Moreover, forces on the lens during accommodation are determined less by the contractile strength of the ciliary muscle, but more by its position and configuration. During contraction, ciliary muscle shortens and moves anterior-internally. In meridional sections, the area of the longitudinal portion decreases, while the area of the circular portion increases, giving the muscle a sharp and prominent inner edge [6,22-24] These changes in muscle configuration cause the relaxation of the zonule and allow the lens to assume a more spherical shape. Interestingly, our study shows that the same changes in muscle configuration during contraction occur also with increasing age. 
Clearly, attempts to capture ciliary muscle in a functional state are subject to artefacts induced by fixation and tissue processing. It has been shown, however, that pharmacologically induced changes in ciliary muscle configuration and position can be preserved to some extend by fixation with aldehydes [6,24-26]. Most of the eyes used in the present study were treated before fixation with tropicamide, which is known to exert a weak cycloplegic action. Some of the eyes were treated with atropine before fixation, but several hours post mortem. However, the pupils of the eyes became mydriatic, indicating that active drug entered the anterior chamber. We do not know to what extent the ciliary muscle of the eyes investigated was relaxed, but it seems reasonable to assume that it was not contracted. Moreover, all eyes were fixed and processed similarly regardless of their age. We therefore assume that in a given eye, ciliary muscle had been fixed in a relatively relaxed, disaccommodated position and configuration. With age, the relaxed ciliary muscle adopts more and more a position anterior-inwardly. A similar position is seen in young eyes after ciliary muscle contraction only.

These findings are in marked contrast to findings in the ciliary muscle of presbyopic rhesus monkeys. In these animals, ciliary muscle becomes fixed in a position far posteriorly with increasing age, as seen in young eyes after relaxation of the muscle.

Moreover, the presbyopic muscle loses its anterior inward movement in response to pilocarpine [6]. It has been shown that this is probably due to an increased stiffness of its posterior tendons, which insert to Bruch's membrane [27]. However, there are also other differences in ageing of the accommodative apparatus between humans and monkeys. In monkeys, the age-related increase in intramuscular connective tissue is minimal compared to that of humans [28]. Also differences were found between monkeys and humans in the ageing of the lens [29]. Thus, although the accommodative system of the two species is very similar, the factors contributing to presbyopia might be different.

What causes the age-related changes in position and configuration of the human ciliary muscle, and how does it relate to presbyopia? The remodelling of the ciliary muscle might bring the muscle in a more favorable position to induce accommodation and to overcome lenticular factors hindering accommodation. The pronounced increase in connective tissue, which is mainly confined to the reticular portion of the muscle, might serve as a kind of internal skeleton to keep the muscle in this more advantageous position. It has been shown that the attachment site of the zonules on the front surface of the lens change as the lens ages and grows [30]. With age the attachment site shifts from the equator onto the anterior lens surface. The zonules might become unable to relax if the front of the enlarged lens is so far from the ciliary muscle that the lens pulls the zonules taut. This might be prevented, at least for a time, by the anterior inward shift of the ciliary muscle position. It might also be the case that the remodelling of the ciliary muscle happens to counteract an agerelated decrease in refractive index of the lens mass. A relaxed ciliary muscle, which 
is positioned more anterior-internally, should cause a more spherical shape of the disaccommodated lens. Donders [17] and Fincham [31] both concluded that the surface of the lens flattens with age, but Brown [32] established in a careful work, that in humans the anterior and posterior curvatures indeed become steeper with age. This finding was called the 'lens paradox' as a steepening of the lens curvature implies rather an increase in refractive power than a decrease as in presbyopia. It has been suggested based on computer simulation experiments that the overall sharpening of lens curvature happens to counteract the concomitant reduction in the index of refraction of the lens mass [2]. Thus the age-related remodelling of the ciliary muscle might be important to maintain emmetropia.

In summary, the age related decline in accommodation seems to be a multifactorial event involving both the ageing of the lens and the ciliary muscle. Although the age processes in lens and muscle are spatially and qualitatively different, they still take place in functional relation with each other. This relationship might be an important factor to guarantee that emmetropia is maintained throughout the whole human life span.

\section{ACKNOWLEDGEMENTS}

We would like to thank Carmen Rummelt for her expert assistance in histology and Marco Gößwein for his excellent preparation of the photographs. This study was supported by the Academy of Science and Literature, Mainz, F.R.G. and by the Deutsche Forschungsgemeinschaft (Dre 124/6-1).

\section{REFERENCES}

1 R.F. Fisher, Presbyopia and its changes with age in the human crystalline lens. I. Physio/. 2lll (1973) 765-779.

2 J.F. Koretz, G.H. Handelman and N.P. Brown. Analysis of human crystalline lens curvature ats a function of accommodative state and age. Vision Re's. 24 (1984) 1141-1151

3 R.A. Weale, Presbyopia. Br. J. Ophthalmol., 46 (1962) 660-668.

4 G. Tönquist. Effect of topical carbachol on the pupil and refraction in young and presbyopic monkeys. Invest. Ophthalmol. Vis. Sit. 5 (1966) 186-195.

5 L.Z. Bito, C.J. DeRousseau, P.L. Kaufman and J.W. Bito. Age-dependent loss of accommodative amplitude in rhesus monkeys: an animal model for presbyopia. Invest. Ophthalmol. Vis. Sit. 2.3 (1982) 23-31.

6 E. Lütjen-Drecoll, E. Tamm, and P.L. Kaufman, Age related loss of ciliary muscle response t pilocarpine in rhesus monkeys. Arch. Ophthalmol., 106 (1988) 1591-1598.

7 M.W. Neider, K. Crawford. P.L. Kaufman and L.Z. Bito. In vivo videography of the rhesus monkey accommodative apparatus. Age-related loss of ciliary muscle response to central stimulation. Arch. Ophthalmol., 108 (1990) 69-74.

8 E. Fuchs, Über den Ziliarmuskel. Albrecht ron Gracfes Arch. Ophthalmol., 120 (1928) 733-741

9 R. Stieve, Über den Bau des menschlichen Ciliarmuskels, seine physiologischen Veränderungen während des Lebens und seine Bedeutung für die Akkommodation. Z. mikroskop. anatom. Forsch. 55 (1949) 3-88.

10 G.O.H. Naumann, Pathologie des Auges. Springer Verlag, Berlin, Heidelberg, New York, 1980.

11 L.G. Luna, Manual of Histologic Staining Methods. McGraw \& Hill, New York, 1986. 
12 Documenta Geigy, Wissenschaftliche Tabellen. 7. Auflage, J.R. Geigy A.G.. Pharma, Basel, 1990.

13 R. Kerschbaumer, Ueber Altersveränderungen der Uvea. Albrecht von Gracfes Arch. Ophthalmol.. 34 (1888) 16-34.

14 G. Attias, Iris und Corpus ciliare. In: Über Altersveränderungen des menschlichen Auges. Albrecht von Graefes Arch. Ophthalmol., 81 (1912) 459-470.

15 P. Rother and G. Leutert, Die Altersveränderungen des Ciliarkörpers. Albrecht von Graefes Arch. Ophthalmol., 168 (1965) 136-149.

16 P. Rother, R. Blume, H. Friedrich and M. Lochner, Die Veränderung der Muskel-BindegewebsRelation des Musculus ciliaris im Laufe des Lebens. Anatom. Anz., 129 (1971) 322-332.

17 F.C. Donders. On the Anomalies of Accommodation and Refraction in the Eyc. New Sydenham Soc.. 1864, London.

18 A. Duane, Studies in monocular and binocular accommodation and their clinical implications. $\mathrm{Am}$ J. Ophthalmol., 5 (1922) 865-877.

19 R. Brückner, Über Methoden longitudinaler Alternsforschung am Auge. Ophthalmologica, Basel. 138 (1959) 59-75.

20 G. Swegmark, Studies with impedance cyclography on human ocular accommodation at different ages. Acta Ophthalmol., 47 (1969) 186-1206.

21 R.F. Fisher, The force of contraction of the human ciliary muscle during accomodation. J. Physiol.. 270 (1977) $51-74$.

22 J.W. Rohen, Der Ziliarkörper als funktionelles System. Gegenhaurs morphol. Jahrh., 92 (1952) 415-440.

23 J.W. Rohen, Das Auge und seine Hilfsorgane. In W.V. Möllendorf and W. Bargmann (eds.), Handbuch der mikroskopischen Anatomie des Menschen, Band III/4, Springer, Heidelberg, 1964.

24 E. Lütjen, Histometrische Untersuchungen über den Ciliarmuskel der Primaten. Albrecht von Graefes Arch. klin. exp. Ophthalmol, 171 (1966) 121-133.

$25 \mathrm{M}$. Flocks and C. Zweng, Studies on the mode of action of pilocarpine on aqueous outflow. $\mathrm{Am}$. J. Ophthalmol., 44 (1957) 380-387.

26 I. Grierson, W.R. Lee and S. Abraham, Effects of pilocarpine on the morphology of the human outflow apparatus. Br. J. Ophthalmol., 62 (1978) 302-313.

27 E. Tamm, E. Lütjen-Drecoll, H.W. Jungkunz and J.W. Rohen, Posterior attachment of ciliary muscle in young. accommodating and old. presbyopic rhesus monkeys. Invest. Ophthalmol. Vis. Sci. 32 (1991) 1678-1692.

28 E. Lütjen-Drecoll, E. Tamm and P.L. Kaufman, Age changes in rhesus monkey ciliary muscle: Light and electron microscopy. Exp. Eye Res., 47 (1988) 885-899.

29 J.F. Koretz, A.M. Bertasso, M.W. Neider, B. True-Gabelt and P.L. Kaufman, Slit-lamp studies of the rhesus monkey eye: II. Changes in crystalline lens shape, thickness and positon during accommodation and aging. Exp. Eye Res., 45 (1987) 317-326.

30 P.N. Farnsworth and S.E. Shyne, Anterior zonular shifts with age. Exp. Eye Res., 28 (1979) 291-297.

31 E.F. Fincham. The mechanism of accommodation. Br. J. Ophthalmol, Mon. Suppl., No. 8 (1937).

32 N.P. Brown. The change in lens curvature with age. Exp. Eye Res., 19 (1974) 175-183. 